\title{
Simulation and Implementation of DVR for Voltage Sag Compensation
}

\author{
D. Murali \\ Research Scholar in EEE Dept., \\ Government College of Engineering, \\ Salem-636 011, Tamilnadu, India.
}

\author{
Dr. M. Rajaram \\ Professor \& HOD / EEE, \\ Government College of Engineering, \\ Tirunelveli-627 007, Tamilnadu, India.
}

\begin{abstract}
Power quality is one of major concerns in the present era. It has become important, especially, with the introduction of sophisticated devices, whose performance is very sensitive to the quality of power supply. Power quality problem is an occurrence manifested as a nonstandard voltage, current or frequency that results in a failure or mis-operation of end user equipments. One of the major problems dealt here is the voltage sag. To solve this problem, custom power devices such as Distribution Static Compensator (D-STATCOM), Dynamic Voltage Restorer (DVR), and Unified Power Quality Conditioner (UPQC) are used. In this paper, DVR, which is the most efficient and effective modern custom power device used in power distribution networks, is employed because of its lower cost, smaller size, and fast dynamic response to the disturbance. This paper presents the simulation analysis of a DVR in MATLAB / SIMULINK environment and its hardware implementation for voltage sag compensation. The results showed clearly the performance of the DVR in mitigating voltage sags
\end{abstract}

\section{Keywords}

DVR, D-STATCOM, MATLAB / SIMULINK, Power Quality, UPQC, Voltage sag compensation.

\section{INTRODUCTION}

With the rapid technology advancements in industrial control processes, electric utilities are experiencing more demanding requirements on the power quality from the large industrial power consumers. The power quality problems in industrial applications concern a wide range of disturbances such as voltage sags and swells, flicker, interruptions, and harmonic distortion. Preventing such phenomena is particularly important because of the increasing heavy automation in almost all the industrial processes. The use of sophisticated electrical and electronic equipments, such as computers, programmable logic controllers, variable speed drives and so forth, very often requires power supplies with very high quality since the failures due to such disturbances usually have a high impact on production costs [1]-[4].

The voltage sag as defined by IEEE standard 1159, IEEE recommended practice for monitoring electric power quality is: "a decrease in RMS voltage or current at the power frequency for durations from 0.5 cycles to $1 \mathrm{~min}$, reported as the remaining voltage". Typical values are between 0.1 and 0.9 per unit and typical fault clearing times range from three to thirty cycles depending on the fault current magnitude and the type of over current detection and interruption $[5,6]$.
Voltage deviations, commonly in the form of voltage sags can cause severe process disruptions and result in substantial production loss. Several recent surveys attribute that $92 \%$ of the disturbances in electrical power distribution systems are due to voltage sags [7]. The loss resulted due to voltage sag problem for a customer at the load-end is huge.

Dynamic voltage restorer (DVR) [8]-[14] and Distribution static compensator (D-STATCOM) provide active solution for voltage sag mitigation. These system-equipment interface devices are commonly known as custom power devices $[3,15]$, in which DVR is a powerful one for short-duration voltage compensation. Unlike the D-STATCOM which connects to the load in parallel, the DVR is connected in series with the sensitive load or distribution feeder and is capable of injecting real and reactive power demanded by the load during voltage sag compensation. However, a DVR cannot provide compensation during full power interruptions. An LC filter is provided at the output of the DVR inverter to attenuate the harmonic contents appearing in injected voltage. The filter parameters are designed according to certain design aspects such as depth of the sag to be mitigated and load voltage.

In this paper, the simulation of DVR in MATLAB / SIMULINK environment and its prototype hardware implementation model are analyzed for voltage sag mitigation in a power system. The results showed the effectiveness and efficiency of DVR in mitigating voltage sags in a low voltage distribution system.

\section{DYNAMIC VOLTAGE RESTORER (DVR)}

Dynamic Voltage Restorer (DVR) is a recently proposed series connected solid state device that injects voltage into the system in order to regulate the load-side voltage. The DVR was first installed in 1966 [16]. It is normally installed in a distribution system between the supply and the critical load feeder [17]. Its primary function is to boost up the load-side voltage in the event of a disturbance in order to avoid any power disruption to that load $[18,19]$. There are various circuit topologies and control schemes that can be used to implement a DVR. In addition to voltage sags and swells compensation, a DVR can also perform other tasks such as: line voltage harmonics compensation, reduction of transients in voltage and fault current limitations. The general configuration of a DVR consists of an injection / booster transformer, a harmonic filter, a voltage source converter (VSC), DC charging circuit and a control and protection system as shown in Fig. 1. In most sag correction techniques, the DVR is required to inject active power into the distribution line during the period of compensation. Hence, the capacity of the energy storage unit 
can become a limiting factor in the disturbance compensation process especially for sags of long duration.

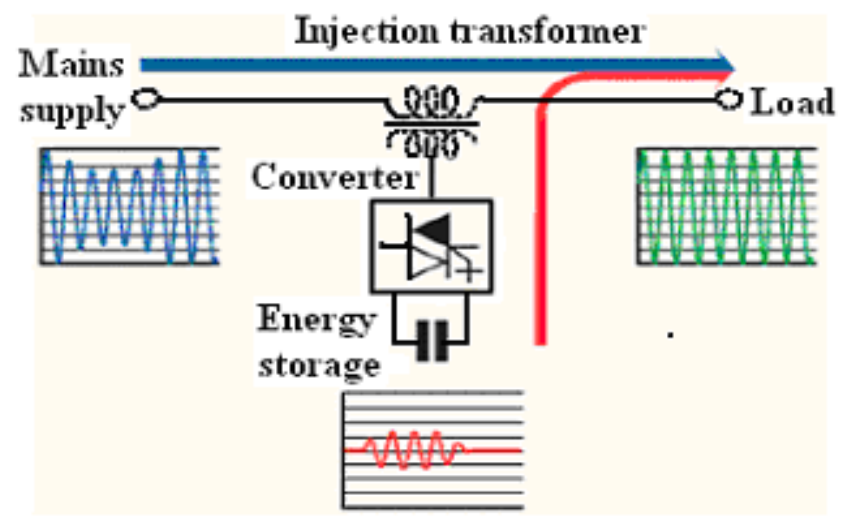

Fig. 1 Principle of DVR

\section{POWER SYSTEM UNDER STUDY}

Consider the power system compensated by a DVR as shown in Fig. 2. The series voltage source inverter (VSI) can generate a sinusoidal voltage with required magnitude, frequency and phase angle. This converter injects a dynamically controlled voltage in series with the supply voltage through the injection transformer to correct the load voltage.

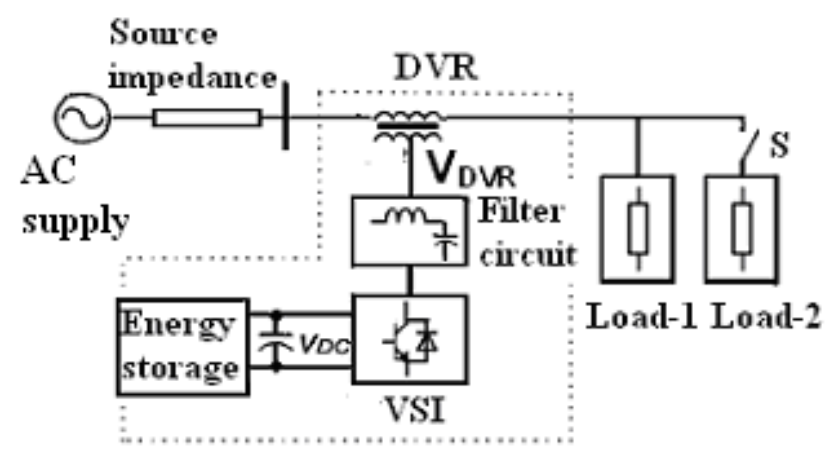

Fig. 2 Schematic diagram of a power system compensated by DVR

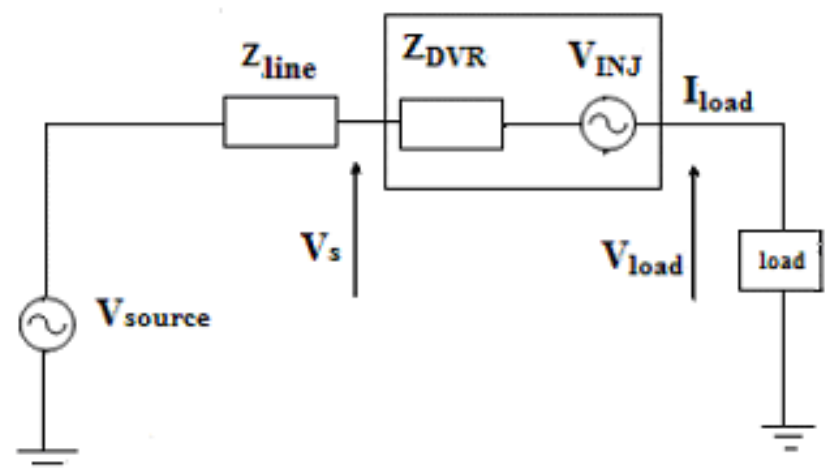

Fig. 3 Equivalent circuit of DVR
A passive filter placed at the high voltage side of coupling transformer rejects the switching harmonic components from the injected voltage. The control scheme is used to maintain a balanced and constant load voltage at the nominal value under system disturbances. There are two resistive loads; load-1 and load- 2 each of $1 \mathrm{~kW}$ rating.

The equivalent circuit of the DVR is shown in Fig. 3. When the source voltage drops or increases, the DVR injects a series voltage $V_{I N J}$ through the injection transformer so that the desired load voltage magnitude $V_{L}$ can be maintained. The series injected voltage of the DVR can be written as:

$$
V_{I N J}=V_{L}+V_{S}
$$

Where, $V_{L}$ is the desired load voltage magnitude.

$V_{S}$ is the source voltage during sags / swells condition.

The load current $I_{L}$ is given by:

$$
I_{L}=\left(\frac{P_{L} \pm j Q_{L}}{V_{L}}\right)
$$

\section{SIMULATION RESULTS DISCUSSION}

The power system shown in Fig. 2 is simulated in MATLAB / SIMULINK environment [20] for the cases of (i). with an additional AC source, and (ii). with DVR. Initially, an additional AC source is connected in the place of DVR. During normal operating condition, there is normal flow of current through load1. At initial state, the load-2 is disconnected from the system during the time interval from 0 to $0.2 \mathrm{sec}$. and no sag problem occurs in the system. During this interval, there is no voltage drop across the transformer primary as shown in Fig. 4. The voltage drop occurs in the transformer primary during the time interval between 0.2 and $0.5 \mathrm{sec}$. because of the load- 2 added to the supply line at $0.2 \mathrm{sec}$. Now the sag problem occurs during the interval from 0.2 to $0.5 \mathrm{sec}$. Then the required voltage is injected by the AC source from $0.5 \mathrm{sec}$. onwards thereby compensating the line voltage and hence the sag problem is eliminated as shown in Fig. 5.

Next, the additional AC source is removed and the DVR is connected in the system. As seen from Fig. 6, the DVR is not injecting any voltage till $0.1 \mathrm{sec}$. as there is no sag problem due to the disconnection of load-2. Then the load-2 is added to the system at $0.1 \mathrm{sec}$. Now the DVR injects voltage from $0.1 \mathrm{sec}$. onwards to mitigate the voltage sag problem. Initially the DVR injects a very small amount of voltage till $0.02 \mathrm{sec}$. for compensating the line drop. The voltages across load-1 and load-2 are shown in Fig. 7 and Fig. 8. Thus the voltages across load-1 and load-2 are almost maintained at constant values by injecting the voltage from DVR. 


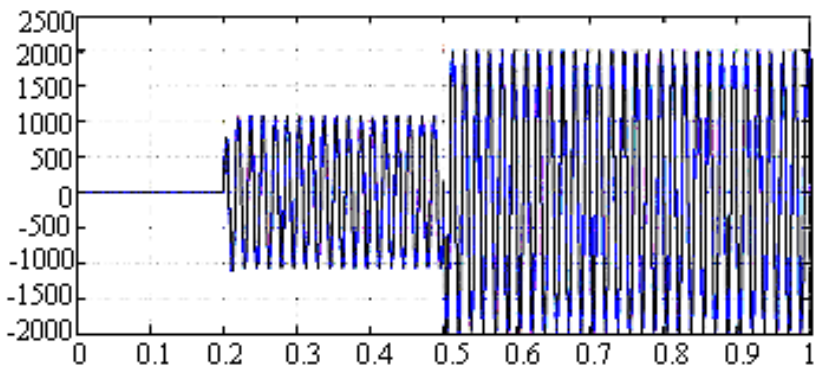

Fig. 4 Variation of voltage (volts) across transformer primary wrt time (seconds) with an additional AC source

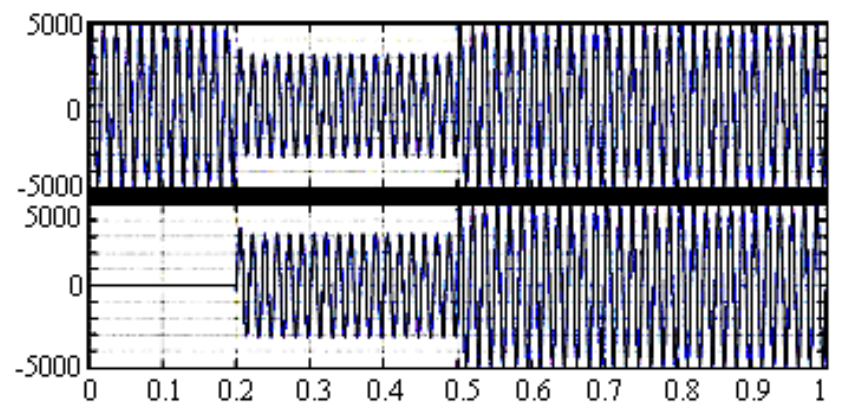

Fig. 5 Variation of voltage (volts) across load-1 and load-2 wrt time (seconds) with an additional AC source

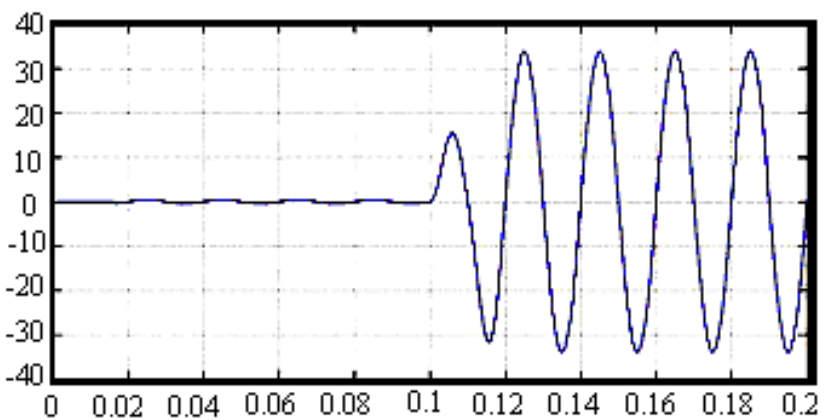

Fig. 6 Variation of injecting voltage (volts) from DVR wrt time (seconds)

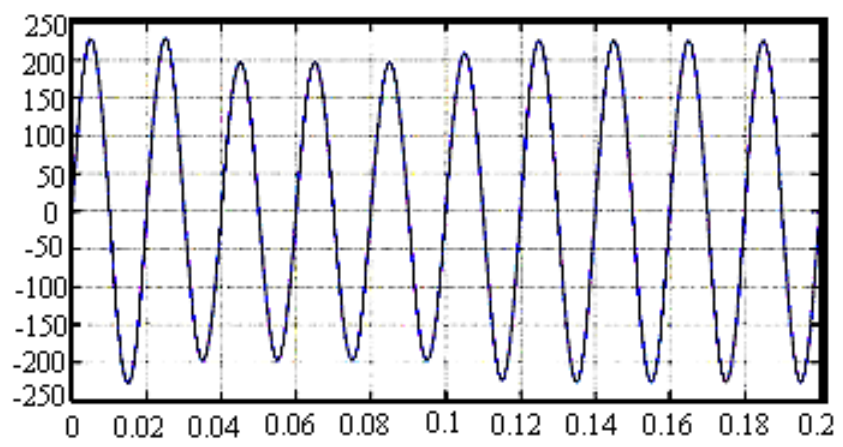

Fig. 7 Variation of output voltage (volts) across load-1 wrt time (seconds) with DVR

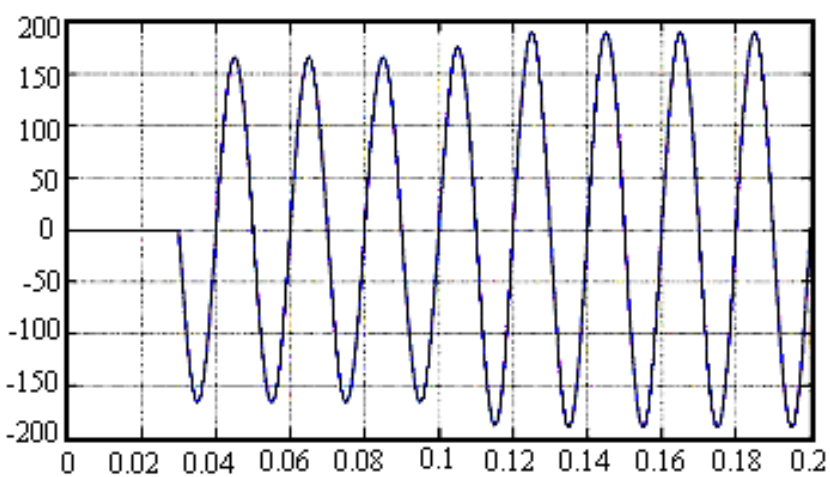

Fig. 8 Variation of output voltage (volts) across load-2 wrt time (seconds) with DVR

\section{HARDWARE IMPLEMENTATION OF DVR}

The block diagram for prototype laboratory model of DVR along with other components is shown in Fig. 9 and the hardware circuit is shown in Fig. 10. During normal condition, the normal voltage appears across the load. The comparator- 2 senses whether the load is in normal state or not. If the system is in normal state, the LCD display indicates "NORMAL STATE". The comparator-1 senses the load continuously. When an extra load is added, the voltage sag problem arises. At that time, the LCD display indicates "VOLTAGE SAG OCCURRED". Then the Comparator-1 gives a signal to the microcontroller. The microcontroller gives the pulses to the relay circuit and DVR circuit. The relay circuit gets closed and the DVR injects voltage to the load. The voltage sag problem is thus eliminated.

When the extra load is removed, the voltage comes to normal value, but DVR injects voltage to the load continuously. The comparator-3 senses load voltage and gives a signal to the microcontroller which trips the relay circuit and stops the pulses to the DVR. The LCD display then indicates "LOAD REMOVED”.

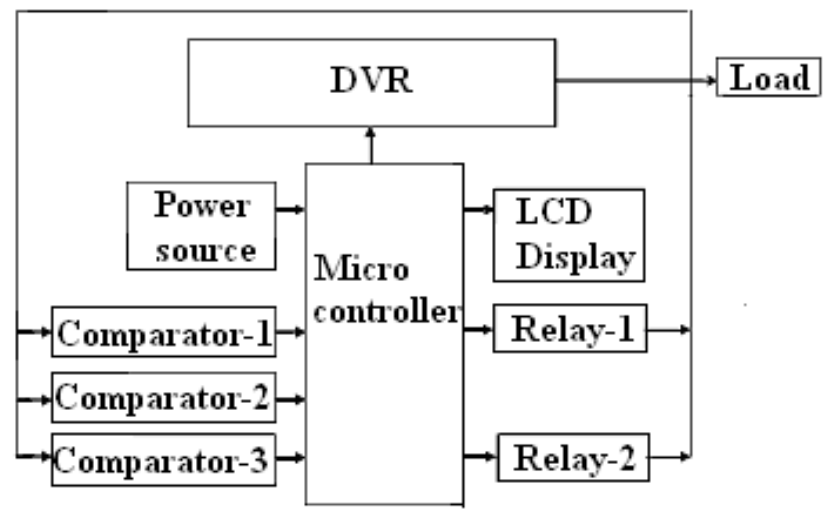

Fig. 9 Block diagram for hardware implementation of DVR 


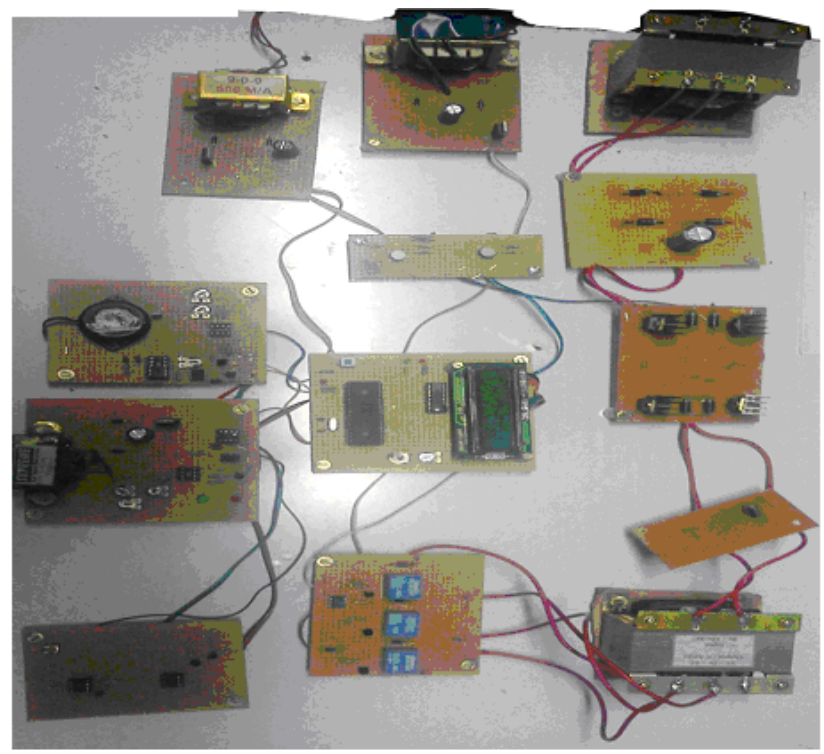

Fig. 10 Hardware circuit

The algorithm for the hardware implementation of DVR is given below:

Step 1: Start the program.

Step 2: Initialize the Port C and Port B of microcontroller.

Step 3: Initialize LCD connected to Port D.

Step 4: Clear the LCD display.

Step 5: Display the "WELCOME".

Step 6: Check whether voltage sag problem occurred or not

Step 7: If "yes", go to next Step, otherwise go to Step 11.

Step 8: Microcontroller passes signals to Relay, Comparator and activates DVR Circuit

Step 9: Repeat Step 3 and Step 4.

Step 10: Display "VOLTAGE SAG OCCURS" and "6V ADDED “

Step 11: Check whether the voltage is in Normal condition or not.

Step 12: If "yes", go to next step, otherwise go to Step 14.

Step 13: Repeat Step 3 \& Step 4 and display "NORMAL STATE".

Step 14: Check whether the voltage is above the Normal level.

Step 15: If "yes", go to next Step, otherwise go to Step 6.

Step 16: Repeat Step 3 \& Step 4 and display "LOAD

$$
\text { REMOVED”. }
$$

\section{CONCLUSION}

In this paper, the simulation of a DVR using MATLAB / SIMULINK software and its prototype hardware implementation have been presented. The simulation results showed clearly the performance of the DVR in mitigating voltage sags. The DVR handled the situation without any difficulties and injected the appropriate voltage component to correct rapidly any changes in the supply voltage thereby keeping the load voltage balanced and constant at the nominal value. In this study, the DVR has shown the ability to compensate for voltage sags; this has been proved through simulation and hardware implementation. The efficiency and effectiveness on voltage sag compensation showed by the DVR makes it an interesting power quality device compared to other custom power devices.

\section{REFERENCES}

[1] Norbert EDOMAH, 2009, "Effects of Voltage Sags, Swell and other disturbances on Electrical Equipment and their Economic Implications," 20th International Conference on Electricity Distribution, Prague.

[2] M.H.J. Bollen, 2000, "Understanding Power Quality Problems - Voltage Sags and Interruptions," Piscataway, New York: IEEE Press.

[3] A. Ghosh, G. Ledwich, 2002, "Power Quality Enhancement using Custom Power Devices," Kluwer Academic Publishers

[4] N.G. Hingorani, 1995, "Introducing Custom Power," IEEE Spectrum, 32(6), pp. 41-48.

[5] IEEE Recommended Practice for Monitoring Electric Power Quality, IEEE Std, 1159-1995, 1995.

[6] IEEE Recommended Practice for Evaluating Electric Power System Compatibility with Electronic Process Equipment, IEEE Std. 1346-1998, 1998.

[7] D.D. Sabin, 1996, "An Assessment of Distribution System Power Quality,” EPRI Final Report, TR-106294-V2, Palo Alto, CA.

[8] E.K.K. Sng, S.S. Choi, D.M. Vilathgamuwa, 2004, "Analysis of Series Compensation DC-link Voltage Controls of a Transformerless Self-charging Dynamic Voltage Restorer," IEEE Transactions on Power Delivery, 19(3), pp. 15111518.

[9] H. Ezoji, A. Sheikholeslami, M. Tabasi, M.M. Saeednia, 2009, "Simulation of Dynamic Voltage Restorer using Hysteresis Voltage Control," European Journal of Scientific Research, 27(1), pp. 152-166.

[10] J.G. Nielsen, M. Newman, H. Nielsen, F. Blaabjerg, 2004, "Control and Testing of a Dynamic Voltage Restorer (DVR) at Medium Voltage Level," IEEE Transactions on Power Electronics, 19(3), pp. 806-813.

[11] N.H. Woodley, L. Morgan, A. Sundaram, 1999, "Experience with an Inverter-based Dynamic Voltage Restorer," IEEE Transactions on Power Delivery, 14(3), pp. 1181-1186.

[12] M. Jazayeri, H. Abdollahzadeh, 2009, “A Novel DVR Control System Design for Compensating all types of Voltage Sags Based on Pre-Fault Method," European Journal of Scientific Research, 33(1),, pp.70-85.

[13] A. Ghosh, G. Ledwich, 2002, "Compensation of Distribution System Voltage using DVR," IEEE Transactions on Power Delivery, 17(4), pp. 1030-1036. 
[14] M. Vilathgamuwa, A.A.D. Ranjith Pcrcra, S.S. Choi, 2002, "Performance Improvement of Dynamic Voltage Restorer with Closad-loop Load Voltage and Current mode Control," IEEE Transactions on Power Electronics, 17(5), pp. 824834

[15] O. Anaya-Lara, E. Acha, 2002, "Modelling and Analysis of Custom Power Systems by PSCAD/EMTDC," IEEE Transactions on Power Delivery, 17(1), pp. 266-272.

[16] B.H. Li, S.S. Choi, D.W. Vilathgamuwa, 2001, "Design Considerations on the line-side filter used in the Dynamic Voltage Restorer," IEE Proc. Generat. Trans. Distribut., 148(1), pp. 1-7.

[17] Rosh Omar, Nasrudin Abd Rahim, Marizan Sulaiman, 2010, "New Control Technique Applied in Dynamic Voltage
Restorer for Voltage Sag Mitigation," American Journal of Engineering and Applied Sciences, 3(1), pp. 858-864.

[18] K. Chan, 1998, "Technical and Performance Aspects of a Dynamic Voltage Restorer," Proceeding of the IEE Half Day Colloquium on Dynamic Voltage Restorers - Replacing Those Missing Cycles, IEEE Xplore Glasgow, UK, pp. 5/1525 .

[19] R. Buxton, 1998, "Protection from Voltage Dips with the Dynamic Voltage Restorer," Proceeding of the IEE Half Day Colloquium on Dynamic Voltage Restorers - Replacing Those Missing Cycles, IEEE Xplore Glasgow, UK, pp. 3/1$3 / 6$.

[20] P. Boonchiam, N. Mithulananthan, 2006, "Understanding of Dynamic Voltage Restorers through MATLAB Simulation," Thammasat Int. J. Sc. Tech., 11(3), pp. 1-6. 